\title{
WHEN DO EMPLOYEES SPEAK UP FOR THEIR CUSTOMERS? A MODEL OF VOICE IN A CUSTOMER SERVICE CONTEXT
}

\author{
CHAK FU LAM \\ Suffolk University \\ DAVID M. MAYER \\ University of Michigan
}

\begin{abstract}
We develop a conceptual model of customer-focused voice and test it in a hospital setting. Drawing from theory and research on voice, we find that customer orientation and job autonomy are positively associated with customer-focused voice. In addition, consistent with social information processing theory, these relationships are moderated by service climate, such that a high service climate compensates for the less desirable aspects of employees or their jobs. Finally, we provide evidence for a critical but untested assumption of the voice literature by linking hospital-level customer-focused voice to hospital-level service performance. Results based on data from four unique data sources, provided at varying points in time, and at different levels of analysis demonstrate support for our conceptual model.
\end{abstract}

Given today's competitive, customer service-oriented business environment, scholars are increasingly interested in examining the role of employee behavior in promoting high-quality customer service (Hong, Liao, Hu, \& Jiang, 2013; Liao \& Chuang, 2007; Liao \& Subramony, 2008; Schneider, Ehrhart, Mayer, Saltz, \& Niles-Jolly, 2005). A particular type of employee behavior that has received considerable attention is customer-focused organizational citizenship behavior (OCB), defined as efforts by employees to take initiative to contribute in ways that serve customer needs (Bettencourt \& Brown, 1997; Bettencourt, Gwinner, \& Meuter, 2001; Dimitriades, 2007; Groth, 2005; Rafaeli, Ziklik, \& Doucet, 2008). Research suggests that when employees are willing to go beyond the call of duty to serve their customers, these customers tend to be more satisfied with their service experience (Bettencourt et al., 2001; Hui, Lam, \& Schaubroeck, 2001). Furthermore, units with employees who

We thank the Ross School of Business at the University of Michigan for the generous funding for this research.

Correspondence and requests for reprints should be addressed to David M. Mayer, University of Michigan, Department of Management and Organizations, Stephen M. Ross School of Business, Ann Arbor, MI 48109 dmmayer@umich.edu. 
engage in more customer-focused OCB tend to perform better financially (Grizzle, Zablah, Brown, Mowen, \& Lee, 2009; Schneider et al., 2005).

Past research on OCB suggests two forms of citizenship behaviors (Grant \& Mayer, 2009; Van Dyne, Cummings, \& Parks, 1995). The first form of OCB is affiliative OCB, which is "interpersonal, cooperative, and noncontroversial" (McAllister, Kamdar, Morrison, \& Turban, 2007, p. 1201). These behaviors are directed toward maintaining the status quo by promoting or supporting existing work processes or relationships (Van Dyne et al., 1995). Affiliative behaviors include helping, showing courtesy, and taking initiative to work additional hours. In the service literature, past research on service-related OCB has primarily focused on these affiliative forms of OCB (Bettencourt \& Brown, 1997; Grizzle et al., 2009; Ilies, Nahrgang, \& Morgeson, 2007; Liden, Sparrowe, \& Wayne, 1997; Schneider et al., 2005). For example, Schneider et al. (2005) studied how leaders promoted service climate within an organization and how such a climate could promote customer-focused helping. Using a sample of 56 departments in stores of a supermarket chain in the eastern United States, these authors found that service leadership behaviors were positively associated with service climate, which in turn, were positively associated with customer-focused OCB. These customerfocused OCB included assisting customers, helping customers with problems beyond what is expected, and doing what it takes to make a customer satisfied.

The second form of $\mathrm{OCB}$ is challenging $\mathrm{OCB}$, which refers to actions directed toward changing the status quo by improving existing work procedures or relationships (Grant \& Mayer, 2009; Van Dyne et al., 1995). Challenging forms of OCB include issue selling (Ashford, Rothbard, Piderit, \& Dutton, 1998; Dutton \& Ashford, 1993), taking charge (Morrison \& Phelps, 1999), and voice (Detert \& Burris, 2007; Morrison, 2011; Van Dyne \& LePine, 1998). Although both affiliative and challenging types of OCB are actions directed at benefiting the work unit or the organization, they differ in that challenge-oriented forms of citizenship behaviors often involve challenging routines and the present state of operations to bring about constructive changes (Morrison \& Phelps, 1999; Van Dyne et al., 1995). In the service literature, challenging forms of OCB have received scant attention (see Bettencourt et al., 2001, for an exception). Therefore, in this article, we focus on a specific form of challenging OCB aimed at improving the customer experience, customer-focused voice, which refers to behaviors that aim to promote, encourage, or cause changes such as developing and making recommendations to management concerning issues that affect customers. We choose to focus on voice in this study because past research on voice argued that in order for organizations to adapt, respond, and make quality decisions on complex business situations, management needs information from employees at lower levels 


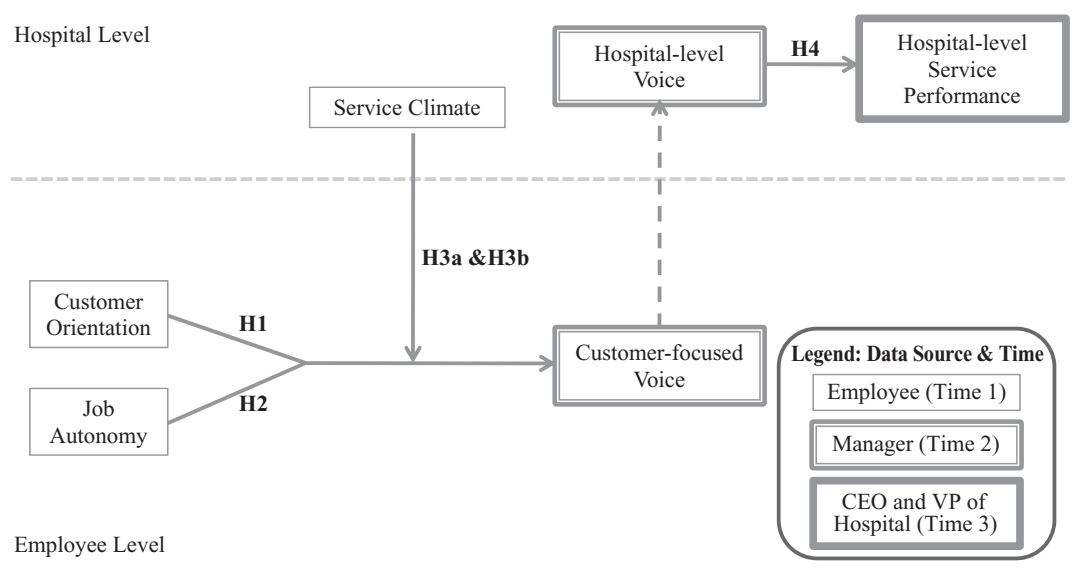

Figure 1: Proposed Theoretical Framework.

Note. Solid and dotted lines refers to the hypothesized effect and the unhypothesized aggregation, respectively.

within the organization to make constructive suggestions (Dutton \& Ashford, 1993; Floyd \& Wooldridge, 1994; Perlow \& Williams, 2003). Lack of voice may delay resource investments in potentially important issues, contributing to confusion and the elevation of costs (Ginzel, Kramer, \& Sutton, 1993). Similarly, in a service context, it has been suggested that "participation OCBs [such as voice] ... are fundamental to the firm's ability to meet the changing needs of its customers" (Bettencourt et al., 2001, p. 30). Given that voice is purported to have beneficial effects on organizational effectiveness (Morrison, 2011) and the economy is increasingly becoming service-based, we believe it is particularly important to study voice within a customer service context.

In this research, we examine both the antecedents and consequences of customer-focused voice. Drawing from current research on voice (Morrison, 2011), we propose two motivational antecedents of customer-focused voice: customer orientation and job autonomy. In addition, we further draw on social information processing theory (Salancik \& Pfeffer, 1978) to make predictions regarding an important boundary condition of these relationships, namely, service climate, defined as 'employees' perceptions of the practices, policies, procedures, and behaviors that get rewarded, supported, and expected," as conducive to meeting customers' needs effectively (Schneider, White, \& Paul, 1998, p. 151). Finally, we examine whether customer-focused voice is significantly associated with ratings of customer service at the organizational level, which is denoted as the hospital level given the current research setting (see Figure 1 for a pictorial depiction of our conceptual model). 
We seek to contribute to the literatures in at least three ways. First and foremost, we aim to contribute to the customer service literature by being one of the first to examine antecedents and consequences of a challenging form of $\mathrm{OCB}$ - customer-focused voice. This is an important contribution because research on voice in other contexts suggests that it has important performance-based outcomes that differ from the more commonly studied affiliative forms of OCB (Van Dyne et al., 1995). Second, we also contribute to the service literature by extending past research on customer service to test for service climate as a moderator of the relationship between personal and job-related factors and customerfocused voice. Finally, we contribute to the voice literature by testing the often stated but heretofore untested assumption underlying much of the voice literature: that voice improves organizational performance. We test this unexamined assumption by aggregating customer-focused voice to the organizational level and linking it to organizational-level service performance. In sum, we seek to make these contributions using data collected from four unique sources, at different levels of analysis, at varying points in time, and in an important service contexthospitals.

\section{Theoretical Development and Hypotheses}

As organizational life becomes increasingly complex, uncertain, and unpredictable, organizations depend on their employees to develop and make improvement recommendations, communicate opinions about work-related issues, and propose new projects or changes in procedures that will benefit the organization (Van Dyne \& LePine, 1998). In this article, we focus on antecedents and consequences of voice aimed to help the customer experience (i.e., customer-focused voice). Voice involves upward communication of ideas, suggestions, or recommendations intended to benefit the workgroup or the organization (Hirschman, 1970; LePine \& Van Dyne, 1998, 2001; Morrison \& Milliken, 2000; Van Dyne, Ang, \& Botero, 2003; Van Dyne \& LePine, 1998). It emphasizes the "expression of constructive challenge intended to improve rather than merely criticize" (Van Dyne \& LePine, 1998, p. 109) and concerns the bottom-up process of lower-level employees making innovative suggestions for change and recommending modifications to standard procedures.

In the customer service literature, concepts similar to customerfocused voice are surprisingly scarce. Although scholars have explored antecedents of more affiliative citizenship behaviors such as going above and beyond to assist or help a customer (Bettencourt \& Brown, 1997; Bettencourt et al., 2001; Grizzle et al., 2009; Payne \& Webber, 2006), a dearth of research has examined the precursors of more 
challenging forms of citizenship that involve providing suggestions to management to improve the customer experience. To our knowledge, Bettencourt et al. (2001) are the only scholars to empirically examine customer-focused voice. Using all self-report data, these authors found that employee personality was positively related to what they refer to as "participation" OCB-defined as taking individual initiative to improve service delivery by the organization. In this research, we build on and expand their investigation of participation by using an established measure of voice that we amended to fit a customer service context, investigating a wide range of antecedents of customer-focused voice based on current theory and research on voice, exploring how service climate functions as a boundary condition of these relationships and examining the consequences of organizational-level voice on organizational service performance using four different sources of data to reduce common-method biases.

\section{Antecedents of Customer-Focused Voice}

To explain what predicts customer-focused voice, we draw from existing theory and research on voice to identify two critical factors that promote employee voice: (a) caring about the beneficiary of the voice, and (b) believing one has the ability to successfully deliver voice in a way that drives organizational change and feels safe to engage in such behavior. Within the domain of customer service and customer-focused voice, we focus on two variables that should influence these two important precursors to voice: customer orientation and job autonomy. First, theory and research on voice has highlighted that a critical determinant of voice behavior is the degree to which employees are concerned about the welfare of the voice beneficiary, such as a coworker, supervisor, the workgroup, organization, or in the case of this research, one's customers (Ashford \& Barton, 2007; Morrison, 2011; Tangirala \& Ramanujam, 2008; Venkataramani \& Tangirala, 2010). In her theoretical review of research on voice, Morrison (2011) posited that the driving motive for voice is the desire to help the organization or work unit perform more effectively as those are the most common beneficiaries of interest to employees. In support of this notion, research shows that other-oriented dispositional characteristics, such as empathy (Joireman, Kamdar, Daniels, \& Duell, 2006) and prosocial motives (Grant \& Mayer, 2009), are positively associated with voice behaviors, in part because these individual characteristics lead employees to be more concerned about the welfare of others, thus encouraging voice behaviors.

Extending this argument, we propose that employees who have greater levels of customer orientation are more likely to engage in customerfocused voice behaviors because they care about the needs of customers. 
Customer orientation is defined as "the importance that service providers place on their customers' needs relating to service offerings and the extent to which service providers are willing to put forth time and effort to satisfy their customers" (Susskind, Kacmar, \& Borchgrevink, 2003, p. 181). It reflects an individual's desire to meet customers' needs and the amount of effort the individual puts forth for customers (Grizzle et al., 2009; Kelley, 1992; Saxe \& Weitz, 1982; Susskind et al., 2003). Prior research has shown that customer orientation is an important predictor of serviceoriented behaviors in both marketing and management research (Brady \& Cronin, 2001; Donavan, Brown, \& Mowen, 2004; Grizzle et al., 2009; Liao \& Subramony, 2008; Susskind et al., 2003). As compared to low customer orientation individuals, employees with high customer orientation understand that customer service is an important aspect of their work, feel responsible for the service they provide, and are dedicated to the needs of their customers. As a result, when they notice issues, errors, or areas for improvement to help the customer experience, they are more likely to speak up, express concerns, and provide recommendations to management to aid their customers. In contrast, low customer orientation employees are unlikely to see customer service as important to them, feel less dedicated to customer service, and see less value in speaking up for their employees. As a result, they have less motivation to speak up and engage in customer-focused voice. In sum, we hypothesize the following:

\section{Hypothesis 1: Customer orientation is positively associated with customer-focused voice.}

Second, research on voice suggests that employees speak up not only when employees care about the needs of a specific beneficiary (i.e., customers) but also when they believe that they can influence their managers to listen to their ideas or suggestions safely and successfully (Ashford et al., 1998; Milliken, Morrison, \& Hewlin, 2003; Withey \& Cooper, 1989). In contrast, those who believe that voice is dangerous and futile are less likely to speak up. For instance, in a qualitative study of silence, Milliken et al. (2003) found that employees were reluctant to speak up when they felt that there was no hope for remedial action and when speaking up could damage their image, career, and relationship with their current managers. Research on issue selling has found similar results. Ashford et al. (1998) found that individual willingness to engage in issue selling behaviors depended on beliefs about whether selling an issue would enhance or damage their image and on beliefs about the probability of successfully getting the attention of the top management team. Specifically, they found that a fit between functional area and the issue sold, perceived organizational support, and relationship quality with top management 
were positively associated with women managers' assessment of probability of selling success and perception of image risk, both of which predicted their willingness to sell women-related issues.

Applying this insight to the current context, we argue that job autonomy is a second important determinant of customer-focused voice. Autonomy refers to the extent to which individuals perceive that they have control or discretion over what they do, how they do it, and when they do it (Hackman \& Oldham, 1976, 1980). There are two reasons why we expect job autonomy to be positively associated with customer-focused voice behaviors. First, high job autonomy signals to individuals that they can do their own work without supervision (Frese \& Fay, 2001; Wrzesniewski \& Dutton, 2001), which enhances their efficacy in engaging in challenging behaviors, such as voice. By contrast, low job autonomy indicates that employees must be told what they have to do. These employees are likely to feel less empowered and have reduced confidence to make a difference in their work environment, which reduces voice. Second, job autonomy can also signal a sense of psychological safety to the employee. When job autonomy is high, employees are allowed to make their own decisions without fear of reprimand or retaliation from their managers. As a result, these employees are more likely to feel that it is safe to challenge the status quo to improve customer service. By contrast, employees with little job autonomy may feel like there is less of a psychologically safe environment to challenge the status quo or workplace procedures. As a result, voice from employees with low job autonomy becomes less likely. Therefore, we posit the following:

Hypothesis 2: Job autonomy is positively associated with customerfocused voice.

Service Climate as a Moderator of the Relationships Between Voice Antecedents and Customer-Focused Voice

In this article, we examine service climate as a boundary condition of the relationship between voice antecedents and customer-focused voice. According to Schneider (1975, p. 470), a work climate refers to perceptions that "are psychologically meaningful molar descriptions that people use to characterize a system's practices and procedures." Thus, the prevailing perceptions of organizational practices and procedures that get rewarded, supported, and expected as conducive to meeting customers' needs effectively constitute service climate (Schneider et al., 1998). When facing a decision on whether or not to speak up about a customerrelated issue, how does an organizational member identify the "right" response? 
To theorize how service climate moderates the relationship between voice antecedents and customer-focused voice, we draw on social information processing theory (Salancik \& Pfeffer, 1978). According to social information processing theory, individuals use their immediate social environment as information to interpret events, to comprehend what behaviors are expected in the immediate environment and their consequences, and to engage in behaviors deemed socially acceptable (Salancik $\&$ Pfeffer, 1978). These cues are then reinforced through reward systems and by providing necessary support. Past research studying the effect of climate has similarly invoked the social information logic to explain its impact on individual attitudes and behaviors. For example, Raub and Liao (2012) argued that "initiative climate can influence individual proactive customer service performance by providing employees with information about expected and rewarded behaviors and thereby creating a strong motivation and desire to engage in proactive behavior" (p. 654). Similarly, Schneider et al. (2005, p. 1019) theorized that "when a service climate signals to employees that service quality behaviors are rewarded, then service-focused OCB is also likely to follow." Consistent with this perspective, empirical research shows that service climate is positively related to customer-focused OCB (Dimitriades, 2007; Schneider et al., 2005), customer perceptions of service quality (Hui, Chiu, Yu, Cheng, \& Tse, 2007; Schneider et al., 1998), customer loyalty (Salanova, Agut, \& Peiro, 2005), customer satisfaction (Dietz, Pugh, \& Wiley, 2004; Mayer, Ehrhart, \& Schneider, 2009; Schneider et al., 2005), individual service performance (Salanova et al., 2005), and unit-level performance (Gelade \& Ivery, 2003; Johnson, 1996; Liao \& Chuang, 2004, 2007; Schneider et al., 2005). Indeed, in a recent meta-analysis of 58 samples with more than 9,000 individuals, Hong et al. (2013) provide a comprehensive review of the service profit chain literature, showing that service climate was positively associated with employee satisfaction, organizational commitment, service performance, and service-oriented OCB.

Applying social information processing theory to the current context, we argue that hospital-level service climate creates the normative standard that customer-focused voice is expected, encouraged, and rewarded in the working environment. Through institutionalized, normative structures, policies, and procedures available to support customer service, the organization signals to employees the priority they should place on customer service. This leads to a compensatory effect of service climate, such that when service climate is higher, employees are more likely to speak up for their customer irrespective of their customer orientation or levels of job autonomy. Specifically, to the extent that employees perceive that delivering high quality service is recognized or rewarded, speaking up about customer-related ideas and recommendations may become a salient 
goal for the employees, no matter their levels of customer orientation or job autonomy.

When service climate is low, employees who are low on customer orientation or job autonomy may feel less inclined to act differently from their primary orientation and thus are expected to be less likely to engage in customer-focused voice. However, when service climate is high, these employees see the rewards associated with engaging in actions that benefit customers, and thus, they are more likely to provide customer-focused voice to management. Similarly, when management communicates about the importance of customer service, employees low on customer orientation or job autonomy may interpret these communications as social cues regarding what is expected from them (even if their normal inclination is not necessarily to be as attuned to customers' needs). Finally, when these employees become aware of the extent to which efforts are made to track the quality of service, they get the message that serving customers is highly valued. Thus, even though employees who are low on customer orientation or job autonomy are inclined to be less customer-focused, the cues they receive from the social environment are highly influential in increasing the amount of customer-focused voice they provide to management.

By contrast, employees high on customer orientation or job autonomy are internally motivated to speak up for their customers. Research on prosocial motivation highlights that employees are willing to subordinate their self-interest for the welfare of others (Bolino \& Turnley, 2005; Meglino \& Korsgaard, 2004; Moon, Kamdar, Mayer, \& Takeuchi, 2008), suggesting that because employees high in customer orientation care about the needs of customers they are likely to speak up irrespective of the service climate. In addition, individuals high in job autonomy feel safer and more efficacious to engage in customer-focused voice. As a result, they are motivated to make suggestions to their immediate boss to improve service delivery irrespective of whether the environment promotes such service behaviors. In sum, we propose the following:

Hypothesis 3: Service climate will moderate the effect of (a) customer orientation, and (b) job autonomy on customer-focused voice such that the effects are stronger when service climate is low.

\section{Hospital-Level Voice as a Predictor of Hospital-Level Service Performance}

Although research on voice has often advocated its importance to organizational effectiveness (Podsakoff, MacKenzie, Paine, \& Bachrach, 2000; Podsakoff, Whiting, Podsakoff, \& Blume, 2009; Walz \& Niehoff, 2000; Yen \& Niehoff, 2004), surprisingly little research to date has 
empirically demonstrated this relationship. To address this gap, we examine how individual customer-focused voice would combine to form a collective phenomenon at the organizational level (i.e., hospital-level customer-focused voice) and would significantly relate to an organizational effectiveness measure (i.e., hospital-level service performance). Specifically, we expect that the attraction-selection-attrition process (Schneider, 1975), socialization, and social information processing and learning processes lead to relatively homogenous behaviors within the same hospital. As a result, we believe that hospital-level customer-focused voice will emerge through a bottom-up process from individual employee customer-focused voice and exist as a collective phenomenon. In particular, we expect hospital-level customer-focused voice will be positively linked with hospital-level service performance for two reasons.

First, we argue that employees provide a strategic link between the external environment and internal operations. By recommending useful changes for customers, managers can then implement these serviceoriented suggestions or feedback for improving service performance in the organization (i.e., hospital). Even if employees' ideas or recommendations are not deemed immediately useful by their managers, these ideas or recommendations may increase the repertoire of ideas for customer-oriented changes that increase an organization's ability to adapt to environmental changes related to customer service. Thus, taking the initiative to make constructive suggestions for customers will help improve the customer service delivery process. By contrast, management in organizations that have employees who provide less voice are not as informed about salient and important customer-related issues, concerns, and suggestions. Hence, they do not attend to these concerns and leave customer-related problems unaddressed, contributing to poorer service performance.

Second, customers may make employees aware of their concerns and suggestions for improving their experience. When these customers see that the concerns or suggestions they expressed have translated into behavior by organizational employees, customers will be pleased with the effort to address their concerns. As a result, they should be more satisfied with the service experience. By contrast, when employees fail to speak up and express ideas to address concerns or issues for customers, the organization may be ill-prepared to tackle customer-related issues when they arise. When customers within the hospitals do not see their issues addressed properly and efficaciously, they will likely be more dissatisfied with the service quality delivered by the organization, resulting in lower levels of organizational-level (i.e., hospital-level) service performance. Thus, we predict:

Hypothesis 4: Hospital-level customer-focused voice is positively associated with hospital-level service performance. 


\section{Method}

\section{Participants and Procedure}

The participating organization is a support service management company that delivers environmental and food services to hospitals. It provides environmental management (e.g., housekeeping, laundry, and patient transportation) and food and nutrition management (e.g., patient dining, senior dining, and clinical nutrition) services. The firm directly places a team of qualified individuals to provide managerial services, ranging from 2 to 11 employees at each site. These individuals serve as supervisors who, on average, oversee eight boundary spanning employees, who are hired by the hospital (not by the participating organization). Employees' daily work includes implementing established procedures and programs that meet goals and ensure a clean and safe environment, conducting quality improvement inspections within assigned areas of responsibility to ensure quality and satisfaction levels meet or exceed expectations, as well as leading and promoting customer service initiatives. At each hospital, there is also an on-site manager who provided ratings for employees' customerfocused voice. The employees almost exclusively express customerfocused voice to these managers. To avoid terminology confusion, we called employees who provided ratings of customer orientation and job autonomy as "employees" and on-site managers who provided ratings for customer-focused voice as "managers." Finally, the chief executive officer (CEO) and vice president (VP) of each hospital provided a rating of the service performance of the participating organization in each hospital.

We employed a research design with three stages of data collection. In the first stage, we sent out an email to all employees, whose contact information was provided by the organization, and invited them to fill out the first survey that included the independent (i.e., customer orientation and job autonomy), moderator (e.g., service climate), and control (i.e., gender, age, and managers' familiarity with employees' work) variables. Employees received a \$5 gift card as a token of appreciation. One month later, we contacted managers at each hospital to provide ratings of the employees' customer-focused voice. Finally, we asked the CEO and VP at each hospital to provide ratings of the hospital-level service performance of the participating organization during the year after we conducted the study. The CEO at each facility was globally involved working with the community and the doctors. In addition, the CEO was the person to whom the participating company would directly report. The CEOs often received critical information from different sources (e.g., nursing department, patient service department, etc.) in the hospital so that they were in a good position to evaluate the overall service performance provided 
by the participating organization in the hospital. Similarly, the VP of the hospital was also knowledgeable about the daily operations of the hospital and in particular the service performance of the participating organization in the hospital. Like the CEOs, the VPs learned about the extent to which the participating organization did a good job at customer service through department heads from the hospital and through hearing compliments and complaints from employees, patients, and visitors in the hospital.

One hundred and ninety-six (out of a possible 210) employees from 41 hospitals filled out the survey, and we obtained 132 matched responses from employees and their manager. We subsequently removed responses from three hospitals with low $R_{\mathrm{wg}}$ values of service climate and voice. In total, we obtained 120 matched responses from employees and their manager from 38 hospitals, representing $57.1 \%$ of the total sample. Employees' mean age was 49.6 years $(S D=9.10$, range $=23$ to 70$)$. About $50 \%$ were female. Employees have worked at the organization for an average of 5.83 years $(S D=7.97$, range $=0$ to 35$)$ and at their current post for an average of 4.87 years ( $S D=6.07$, range $=0$ to 25 ). In addition, $26.7 \%$ of the employees held a high school or G.E.D. diploma, $40.8 \%$ some college or an associate degree, $23.3 \%$ a college/university degree, and $9.2 \%$ a master's degree. Unfortunately, the organization was unable to provide us with demographic information on the managers, CEOs, and VPs.

\section{Measures}

We asked employees to respond to the items with the following prompt, "To what extent do you agree with the following statement?" Unless otherwise noted, all multi-item scales were assessed from $1=$ strongly disagree to $7=$ strongly agree.

Customer orientation. We employed Susskind et al.'s (2003) measure of customer orientation. A sample item is "As an employee responsible for providing service, customers are very important to me." The coefficient alpha was .78.

Job autonomy. We assessed job autonomy using a subdimension of the individual empowerment scale (Spreitzer, 1995). A sample item is "I have significant autonomy in determining how I do my job." The coefficient alpha was .85 .

Service climate. We used Schneider et al.'s (1998) seven-item measure of service climate. A sample item is "How would you rate the recognition and rewards employees receive for the delivery of superior service in your department?" Employees made responses based on their evaluation on a 
rating scale from $1=$ very poor to $7=$ excellent. The coefficient alpha was .84 .

Customer-focused voice. We adapted four items from Van Dyne and LePine's (1998) measure of voice to fit a customer service context. Consistent with recent research measuring voice (Grant, Parker, \& Collins, 2009), these items were adopted on the basis that they were closest to the current definition of customer-focused voice. The items include "he/she developed and made recommendations concerning issues that affect our customers," "he/she spoke up and encouraged others in this group to get involved in issues that affect customers," "he/she communicated his/her opinions about customer-related issues to others in the group even if his/her opinion was different and others in the group disagreed with him/her," and "he/she spoke up in this group with ideas for new projects or changes in procedures for the customers." To further understand the characteristics associated with customer-focused voice, we conducted informal interviews with several employees in a large midwestern U.S. hospital, and our interviews further revealed that employees were encouraged to raise and report service-related issues to their manager to ensure service quality. With the help of the informants, as well as the CEO of the company, we included four additional items to assess customer-focused voice: "he/she said something to his/her boss when he/she discovered potential customer service problems," "he/she voiced his/her concerns about customer service to his/her boss even when the customer was unaware of it," "When he/she sensed there might be a customer service concern, he/she spoke to his/her boss," and "He/she spoke up about a customer service problem he/she anticipated might happen." The eight-item customer-focused voice scale had an overall coefficient alpha of .89 .

Hospital-level service performance. To measure the service performance at the hospital, we asked the CEO at each hospital the following question: "How would you score the current level of service at your hospital?" The response scale ranged from $1=$ very poor to $5=$ excellent. In addition, as part of the participating organization's effort to keep track of their own service performance, the VP at each hospital was also asked the following question with regard to the service performance provided by the participating organization: "[Name of participating organization] continually strives to improve customer satisfaction." The response scale ranged from $1=$ disagree strongly to $5=$ agree strongly. Although the CEOs and VPs assessed single-item measures, we found a significant relationship between the VP's and CEO's rating of service performance $(r=.61, p<.05)$, suggesting that there is some consistency in the perceptions of the service performance of the participating organization in each hospital. 
Controls. Consistent with prior research on service-oriented behaviors (e.g., Joshi, Liao, \& Jackson, 2006), we included several demographic control variables including age and gender. We also included managers' frequency of interaction with the employees in our analyses as a control variable to account for both the liking effect between the employees and the managers as well as how familiar the managers are to the work of the employees. Furthermore, we included the number of years employees had worked with the manager as a control as those who had worked longer may have developed a greater level of trust with their manager, which in turn, facilitates voice (Ashford et al., 1998). Finally, we included several control variables at the hospital level such as size of the hospital (in thousands of square footage) and the number of years the hospital has employed the service of the participating organization.

\section{Results}

\section{Descriptive Statistics}

Means, standard deviations, and correlations for the key variables appear in Table 1(A) and (B). Based on the bivariate correlations, older employees performed significantly less customer-focused voice than younger employees $(r=-.22, p<.05)$, providing some support for our use of age as a control variable. Frequency of interaction between the employees and the managers had a positive relationship with ratings of customerfocused voice $(r=.40, p<.01)$, suggesting that the more frequent the managers interacted with the employees, the higher the ratings they gave to the employees. On a hospital level, hospital-level customer-focused voice is positively associated with CEO rating of service performance $(r=.33, p<.05)$ and is unrelated to VP rating of service performance even though the relationship is in the expected direction $(r=.24, n s)$. This suggests that it is important to covary out some of the hospital-level variables to provide an accurate test of the relationship between hospital-level customer-focused voice and service performance.

\section{Data Aggregation}

We generated service climate values by aggregating employee data to the hospital level. First, we assessed the degree of interrater agreement regarding hospital-level service climate by calculating the $R_{\mathrm{wg}}(j)$ statistic (George \& James, 1993). The mean $R_{\mathrm{wg}}(j)$ for service climate among the original 41 participating hospitals was .67 , which is slightly lower than the 
TABLE 1

Means, Standard Deviations, and Correlations Among Individual-Level Study and Hospital-Level Study Variables

\begin{tabular}{|c|c|c|c|c|c|c|c|c|}
\hline Variable & Mean & $S D$ & 1 & 2 & 3 & 4 & 5 & 6 \\
\hline \multicolumn{9}{|c|}{ (A) Individual-level study variables } \\
\hline 1. Gender & .50 & .50 & & & & & & \\
\hline 2. Age & 49.64 & 9.10 & .12 & & & & & \\
\hline 3. Interaction frequency & 3.94 & .96 & -.04 & -.04 & & & & \\
\hline 4. Customer orientation & 6.86 & .31 & $.21 *$ & .02 & -.03 & & & \\
\hline 5. Job autonomy & 5.86 & .99 & .02 & -.05 & $-.20 *$ & .14 & & \\
\hline 6. Service climate & 5.57 & .81 & .03 & 11 & -.01 & $.26 *$ & $.44 * *$ & \\
\hline 7. Customer-focused voice & 5.49 & .90 & -.03 & $-.22 * *$ & $.40 * *$ & .02 & .12 & .14 \\
\hline \multicolumn{9}{|l|}{ (B) Hospital-level study variables } \\
\hline $\begin{array}{l}\text { 1. Hospital size (in } \\
\text { thousand square footage) }\end{array}$ & 490.50 & 366.53 & & & & & & \\
\hline $\begin{array}{l}\text { 2. Hospital length of } \\
\text { service (in years) }\end{array}$ & 8.57 & 6.47 & -.10 & & & & & \\
\hline 3. Service climate & 5.35 & .82 & -.34 & -.03 & & & & \\
\hline $\begin{array}{l}\text { 4. Hospital-level } \\
\text { customer-focused voice }\end{array}$ & 5.31 & .72 & .29 & -.11 & .13 & & & \\
\hline $\begin{array}{l}\text { 5. Hospital-level service } \\
\text { performance (CEO } \\
\text { rating) }\end{array}$ & 4.23 & .57 & -.14 & -.07 & .46 & $.33 *$ & & \\
\hline $\begin{array}{l}\text { 6. Hospital-level service } \\
\text { performance (VP rating) }\end{array}$ & 4.00 & .73 & -.05 & -.06 & .27 & .24 & $.61 *$ & \\
\hline
\end{tabular}

Note. (A) $N=120$ (Level-1). Gender is coded such that female equals 0 and male equals 1. (B) $N=38$ (Level-2). $\mathrm{CEO}=$ chief executive officer; $\mathrm{VP}=$ vice president.

$* p<.05$, two-tailed. ${ }^{*} p<<.01$, two-tailed.

generally accepted .70 value. As a result, we identified and subsequently removed three hospitals with extreme low levels of agreement. The resulting $R_{\mathrm{wg}}(j)$ for service climate was .84. In addition, we computed intraclass correlations (ICCs) to determine the reliability of service climate (Bliese, 2000). We used the ICC(1) to examine the degree of variability in responses at the individual level that is attributable to being part of a given hospital and the $\operatorname{ICC}(2)$ to examine the reliability of group means. The ICC(1) was .21 $(p<.05)$ and the ICC(2) was .45. We employed similar procedures to compute customer-focused voice at the hospital level. The mean $R_{\mathrm{wg}}(j)$ for customer-focused voice was .81 . In addition, the ICC(1) was $.15(p<.05)$ and the $\operatorname{ICC}(2)$ was .35 . Although the ICC $(2)$ values are smaller than typically desired, given the small group sizes and the fact that ICC(2) values are in part a function of group size the values are not surprising. In sum, these values provide adequate support for aggregation (Bliese, 1998; Bliese, Halverson, \& Schriesheim, 2002). 
TABLE 2

Results of Multilevel Analysis of the Interaction Between Voice Antecedents and Service Climate on Customer-Focused Voice

\begin{tabular}{|c|c|c|c|c|}
\hline \multirow[b]{2}{*}{ Variable } & \multicolumn{4}{|c|}{ Customer-focused voice } \\
\hline & Null model & Model A & Model B & Model C \\
\hline \multicolumn{5}{|l|}{ Level 1} \\
\hline Intercept & $5.43 * *$ & $5.43 * *$ & $5.46^{* *}$ & $5.42 * *$ \\
\hline Gender & & .02 & .02 & -.03 \\
\hline Age & & $-.02 *$ & $-.02 *$ & $-.03 * *$ \\
\hline Interaction frequency & & $.36^{* *}$ & $.36^{* *}$ & $.37 * *$ \\
\hline Number of years with manager & & $.06^{*}$ & $.06^{* *}$ & $.06 * *$ \\
\hline $\mathrm{CO}$ & & & $.48^{*}$ & $.50 *$ \\
\hline Job autonomy & & & $.20^{*}$ & $.21 *$ \\
\hline \multicolumn{5}{|l|}{ Level 2} \\
\hline Service climate & & & & .22 \\
\hline \multicolumn{5}{|l|}{ Cross-level } \\
\hline $\mathrm{CO} \times$ service climate & & & & $-.72 *$ \\
\hline Job autonomy $\times$ service climate & & & & $-.53 * *$ \\
\hline Degrees of freedom & & 37 & 37 & 37 \\
\hline Pseudo- $R^{2 \mathrm{a}}$ & & .37 & .47 & .49 \\
\hline
\end{tabular}

Note. $N($ Level-1 $)=120 ; N($ Level-2) $=38$. Entries corresponding to the predicting variables are estimations of the fixed effects, gamma $(\gamma)$, with robust standard errors. Italicized variables are hypothesized variables; the other variables are control variables. $\mathrm{CO}=$ customer orientation.

a Pseudo- $R^{2}$ values were calculated on the basis of the formula from Kreft and De Leeuw (1998).

$* p<.05 . * * p<.01$.

\section{Hypotheses Tests}

Given the nested nature of the data (employees nested within hospitals), to test our hypotheses we conducted random coefficient modeling (commonly referred to as hierarchical linear modeling, or HLM; Raudenbush, Bryk, Cheong, \& Congdon, 2001). In this study, we treated our independent variables (i.e., customer orientation and job autonomy) as Level-1 (i.e., individual) variables and service climate as a Level-2 (i.e., hospital) variable. We used HLM 6.0 to analyze the hierarchical linear model.

Our hypotheses stated that customer orientation (Hypothesis 1) and job autonomy (Hypothesis 2) would be positively associated with customerfocused voice. As indicated in Table 2, the coefficients of the main effects are significant for (a) customer orientation $\left(\gamma_{50}=.48, p<.05\right)$, and (b) job autonomy $\left(\gamma_{60}=.20, p<.05\right)$, providing support for Hypotheses 1 and 2 .

Hypotheses $3 \mathrm{a}$ and $3 \mathrm{~b}$ proposed that voice antecedents (i.e., customer orientation and autonomy) would interact with service climate such that 
(a)

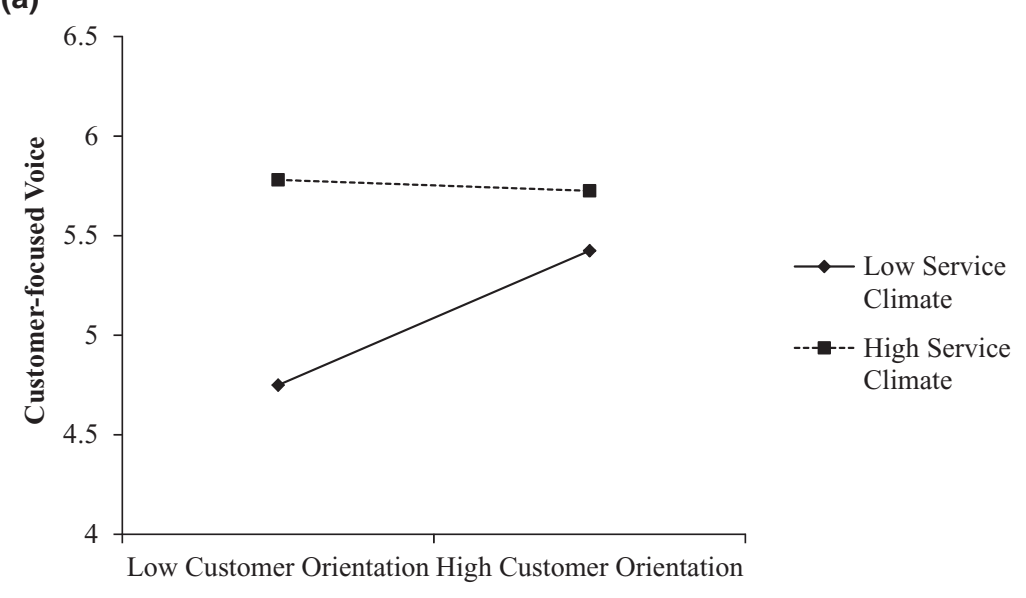

(b)

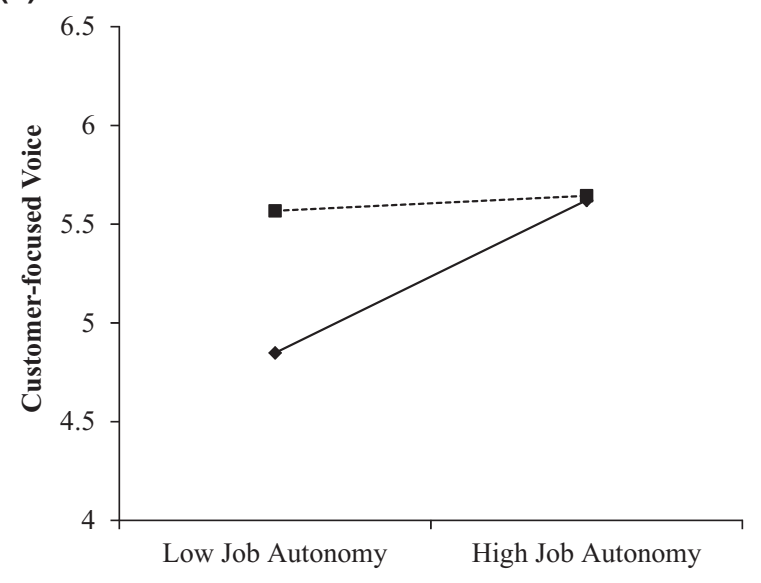

$\longrightarrow$ Low Service Climate

--- -- High Service Climate

Figure 2: (a) Interaction Between Customer Orientation (CO) and Service Climate. (b) Interaction Between Job Autonomy and Service Climate.

the impact of voice antecedents would be weaker when levels of service climate are high. The results in Model $\mathrm{C}$ of Table 2 provide full support for these hypotheses. Specifically, the coefficients of the interactive term (voice antecedents $\times$ service climate) are significant for the interaction between (a) customer orientation and service climate $\left(\gamma_{51}=-.72, p<\right.$ $.05)$, and (b) job autonomy and service climate $\left(\gamma_{61}=-.53, p<.01\right)$. In line with prescriptions from Aiken and West (1991), we plotted these interactions in Figure 2(a) and (b). Consistent with Hypotheses 3a and 3b, 
TABLE 3

Results of Regression Analyses of the Effect of Hospital-Level Customer-Focused Voice on Hospital-Level Service Performance

\begin{tabular}{lcc}
\hline \hline & CEO rating & VP rating \\
Predictors & $\beta$ & $\beta$ \\
\hline Hospital size & .00 & .00 \\
Hospital length of service & -.01 & -.02 \\
Hospital-level service climate & $.31^{*}$ & .08 \\
Hospital-level customer-focused voice & $.43^{*}$ & $.71^{*}$ \\
Degrees of freedom & $(4,33)$ & $(4,33)$ \\
Adjusted $R^{2}$ & .27 & .15 \\
\hline
\end{tabular}

Note. $N=38 . \mathrm{CEO}=$ chief executive officer; $\mathrm{VP}=$ vice president.

$* p<.05$.

the relationships between voice antecedents and customer-focused voice are weaker when service climate is high. Simple slope results further indicated that for individuals working in a high service climate hospital (one SD above the mean), customer orientation $(\beta=-.08, n s)$ and job autonomy $(\beta=.11, n s)$ are unrelated to customer-focused voice. In contrast, for individuals working in a low service climate hospital (one SD below the mean), customer orientation $(\beta=.72, p<.01)$ and job autonomy $(\beta=.75, p<.01)$ are significantly related to customer-focused voice in the expected direction. Thus, Hypotheses $3 \mathrm{a}$ and $3 \mathrm{~b}$ are fully supported.

Hypothesis 4 predicted that hospital-level customer-focused voice would be positively associated with hospital-level service performance. To examine Hypothesis 4, we conducted an ordinary least square (OLS) regression. We regressed hospital-level service performance, separately for CEO's and VP's rating, on control variables (i.e., size of hospital and length of service at the hospital), hospital-level service climate, and hospital-level customer-focused voice. As indicated in Table 3, hospital-level customer-focused voice was positively associated with hospital-level service performance rated by both the CEO $(\beta=.43$, $p<.05)$ and the VP $(\beta=.71, p<.05)$. Therefore, Hypothesis 4 is also supported.

\section{Discussion}

In this study, we explore the antecedents, a boundary condition, and a consequence of a challenging form of OCB-customer-focused voice. Drawing from theory and research on voice, we proposed and found that customer orientation and job autonomy are positively related to 
customer-focused voice. In addition, we found that service climate moderates the relationship between voice antecedents and customer-focused voice such that these relationships are stronger when service climate is low. These interactions reveal that a high service climate compensates for unfavorable conditions for customer-focused voice, such as low customer orientation and low job autonomy. Finally, we provide evidence that customer-focused voice aggregated to the hospital level is positively related to hospital-level service performance rated by two independent sources, highlighting the importance of voice at the organizational level in a customer service context.

\section{Theoretical Implications}

Our findings offer several important theoretical implications to the customer service and voice literatures. First and foremost, we add a fresh perspective on research on customer service by building a preliminary nomological network of customer-focused voice. Whereas prior research on customer service has focused primarily on what predicts affiliative forms of customer-focused OCB, such as helping customers (e.g., Grizzle et al., 2009; Schneider et al., 2005), our study focuses on how employees interact with their managers to promote the welfare of their customers through challenging forms of customer-focused OCB, such as voice. These behaviors are similar in that both are concerned with benefiting the customers. However, whereas the target of communication for the former tends to be the customer themselves and generally involves directly helping a customer, the latter focuses on providing ideas and suggestions to managers to improve the customer experience. Given the benefits that have been purported about voice (Dutton \& Ashford, 1993; Floyd \& Wooldridge, 1996), we make an important contribution by highlighting several antecedents of voice within a customer service context.

We also add new insights into the role of service climate in predicting customer-related outcomes. Although organizational scholars have accumulated considerable evidence regarding the positive relationships between service climate and a variety of customer-related outcomes (Hong et al., 2013; Liao \& Chuang, 2007; Schneider et al., 1998, 2005), there is less understanding of how service climate may moderate the relationship between personal and organizational factors and employee behavior aimed at improving the customer experience and customer satisfaction. Fortunately, recent work has started to examine service climate as a moderator of the relationship between aspects of the service context such as the frequency of customer contact, intangibility of the service, and service employee task interdependence and customer satisfaction (de Jong, 
de Ruyter, \& Lemmink, 2004; Dietz et al., 2004; Mayer et al., 2009). For instance, McKay, Avery, Liao, and Morris (2011) found that service climate moderated the relationship between diversity climate and customer satisfaction. In this article, we build on this burgeoning literature by examining the interaction between antecedents of voice and service climate in predicting customer-focused voice. Our findings suggest that service climate helps organizations to overcome some of the deterring factors of customer-focused voice by encouraging employees to speak up for their customers even when they lack a high customer orientation or high job autonomy. Thus, our work extends extant research (Hong et al., 2013) by examining how service climate moderates the relationship between individual-level factors and customer-focused voice.

It is important to note that one other study has some similarities to aspects of our study. Grizzle et al. (2009) found that employee customer orientation interacts with unit customer orientation climate (a concept sharing much conceptual overlap with service climate) to predict affiliative customer-oriented behaviors, such as trying to satisfy customers, getting customers to discuss their needs, or answering customers' question correctly. Our study differs from their study in a significant way. Specifically, Grizzle et al. (2009) found that customer orientation climate and individual customer orientation have an additive, synergistic interaction: The impact of the interaction on affiliative service-oriented behaviors is greatest when customer orientation climate is present and when individuals are dedicated to the needs of the customers. In contrast, our findings suggest a compensatory interaction, in which the environment compensates and offsets the effect of a focal individual variable (see Balliet, $\mathrm{Li}$, \& Joireman, 2011; Lam, Huang, \& Janssen, 2010; and Rodriguez, Perez, \& Guiterrez, 2008 for recent examples of compensatory forms of personsituation interactions). In the current context, we propose and find that service climate is especially critical in promoting customer-focused voice for employees low on customer orientation or job autonomy.

There are several reasons to explain these inconsistent findings. From a theoretical perspective, one possible explanation for the discrepancy is related to the target of customer-focused behavior. In the current study, the target of voice is the employee's immediate boss, as opposed to the customers themselves (such as in Grizzle et al., 2009). If high service climate serves the intended effect of signaling that customer service is rewarded or supported in the workplace, then those low on customer orientation may become especially motivated to show that they are dedicated to the customer through impressing their immediate boss. As a result, low customer-orientation employees may be motivated to engage in voice to impress their supervisor directly, as opposed to helping their customers, 
which may or may not be observed by their immediate boss for future rewards.

From a methodological perspective, too, we believe it is more likely that our pattern looks different from Grizzle et al. as a result of the use of different measures (customer orientation climate versus service climate), different samples (service workers at chain restaurants versus employees working in a hospital setting), and different dependent variables (affiliative customer-oriented behavior versus challenging customer-focused voice). These conflicting findings suggest that although there appears to be value in examining the person $\times$ service environment interaction, more research is warranted to determine the nature of the interaction or the conditions under which the interactions take different forms.

Finally, we also contribute to the voice literature by being the first to find a positive relationship between voice and organizational-level performance. According to Detert and Edmondson (2011, p. 462), speaking up is vital to the success of an organization because it "brings problems and opportunities for improvement to the attention of those who can authorize action." Within a service context, Bettencourt et al. (2001) assert that challenging forms of OCB, such as customer-focused voice, is critical toward addressing a firm's ability to adapt to the changing needs of its customers. Despite these claims, past research on voice has primarily focused on the effect of voice on the voicer, such as performance evaluations (Grant et al., 2009; Whiting, Maynes, Podsakoff, \& Podsakoff, 2012), intentions to quit and job search activities (Olson-Buchanan \& Boswell, 2002), and salary progression and promotion (Burris, 2012; Seibert, Kramer, \& Crant, 2001). Lacking in past empirical research is a focus on whether employees' voice actually translates into unit-level or organizational-level performance. Our empirical findings highlight a positive link between voice and organizational-level service performance, thus contributing to a more complete understanding of why voice matters in organizations.

\section{Practical Implications}

Our findings offer several practical implications. First, our study points toward the value of encouraging employee customer-focused voice. Given that employees act as a strategic link between the external environment and internal operations, it is critical that when employees notice customerrelated issues, they feel safe and comfortable to share their opinions, suggestions, and recommendations to management. Our finding suggests that there is a clear beneficial effect for organizations to encourage employees to express their voice to best serve customers. Second, our results 
suggest that organizations should try to develop a service climate even when it may be "costly in terms of time, money, and resources to successfully develop and maintain a high service climate" (Mayer et al., 2009, p. 1045). Developing a service climate is costly on many levels. It involves developing a selection system that brings in employees who are likely to focus on customer service. It also involves using training and socialization programs to emphasize the importance of customer service and to provide requisite tools. Managers may need to be trained regarding how to evaluate service performance in performance appraisals. Employees must have the necessary equipment to deliver high quality service. Still, this research suggests that when employees are less inclined to be sensitive to customers' needs and have little control over their work, a high service climate is especially important to promote customer-focused voice. Therefore, investing resources to develop a service climate in these situations makes the most sense for organizations. Third, it is important for hiring and job design processes to be utilized to improve the customer experience. For example, hiring employees high in customer orientation should prove fruitful. It is also possible to socialize and train employees to have higher levels of customer orientation. In addition, it is important to structure jobs so that employees have more autonomy as this promotes customer-focused voice.

\section{Limitations and Future Directions}

We acknowledge that our findings should be considered in light of several limitations. First, we were not able to directly examine the psychological mechanisms by which customer orientation and job autonomy influence customer-focused voice. We encourage researchers to investigate multiple psychological mechanisms that may explain the relationship between these customer-focused voice antecedents and customer-focused voice.

Second, consistent with extant field research in the service literature, our data are all based on survey research. As a result, we cannot draw causal conclusions from our study. In this study, we collected our data over time to reduce concerns about reverse causality. Moreover, we collected our data from four different sources, ranging from the respondents, their immediate supervisor, as well as two top members of upper management in the hospital to ensure that our data are not subject to common method biases. Still, we encourage future research to examine customerfocused voice using a more controlled, perhaps field experiment such as those conducted by Hui et al. (2001), in which service leaders receive service training to improve customer service. Future research employing a 
field experiment to investigate what predicts customer-focused voice will clarify the causal relationship between voice antecedents and customerfocused voice.

A third limitation is that, although we found a positive relationship between hospital-level customer-focused voice and hospital-level service performance, future research is needed to further elucidate possible curvilinearity and boundary conditions of the relationship between unit-level customer-focused voice and service performance. For instance, the effect of unit-level voice on unit-level performance may depend on the feasibility of voice, or the extent to which an issue is perceived to be achievable and realistic (Dutton \& Duncan, 1987). On the one hand, when suggestions are useful and feasible, supervisors can endorse these ideas and make customer service delivery more effective. On the other hand, when suggestions or recommendations raised by employees within a unit cannot be easily applied, the unit might be distracted from focusing on service issues that demand more urgent attention than those raised by employee's voice. Thus, feasibility of a voice idea might be a contingent factor in determining the effect of unit-level voice on unit-level performance. Another possible contingent factor that might alter the relationship between unit-level customer-focused voice and unit-level service performance is task interdependence, defined as the degree to which group performance calls for coordinated interactions among members (Campion, Medsker, \& Higgs, 1993; Saavedra, Earley, Van Dyne, \& Lee, 1993). As tasks becomes more interdependent, suggestions for improvement lead groups to better improve their work processes, enhancing the quality of service delivered to the customers. Finally, as we proposed and found in this article, voice should be positively related to service performance as it is aimed toward benefiting critical organizational stakeholders. However, voice could possibly hurt service performance if continually pushing the customer's interests may require unreasonable, cost-ineffective accommodations. This suggests a possible nonlinear, inverted-U effect of unit-level voice on unit-level service performance (MacKenzie, Podsakoff, \& Podsakoff, 2011). We encourage future research to further explicate the effect of unit-level voice on unit-level performance, and explore potential moderators of this effect.

Fourth, our analysis is based on 120 employees from 38 hospitals, which is small compared to other research on customer service. Furthermore, our analyses were based on two or three informants per hospital and may therefore be unstable and subject to sampling error. The obtained ICC(2) values raised the additional concern that the aggregated measure of hospital-level voice does not represent homogenous and different units, as the group means across hospitals were not reliably different. Nevertheless, our sample size is comparable to the study reported by 
Grizzle et al. (2009), and we have largely found significant results with our hypotheses in spite of the relatively sample size. In addition, we note that a major cost of the company is the salary of the people they place at the hospital, and as such, the participating organization makes every effort to avoid overstaffing at each hospital to reduce personnel costs. Therefore, it might be the case that there are only two or three informants at each hospital. Finally, $\operatorname{ICC}(2)$ values are highly influenced by group size and it is common in the literature for values to be low-especially with relatively small group sizes (Bliese, 1998; Bliese, Halverson, \& Schriesheim, 2002). Given the high $R_{\mathrm{wg}}$ values, we are confident that our hospital-level data are stable and exhibit little sampling error. However, future research will benefit from having more units and more respondents per unit to minimize sampling error.

Fifth, the mean level of customer orientation is quite high, and as a result, there might be concerns about whether service climate would have a positive impact when customer orientation goes below the customer orientation midpoint. Although we do not have data to support this contention, if customer orientation is extremely low it is possible that even having a high service climate might not be enough to motivate employees to engage in customer-focused voice. However, prior research (Susskind et al., 2003) using this measure of customer orientation reveals a mean of 4.23 and a standard deviation of .39 (on a five-point scale). Similarly, Grizzle et al. (2009) reported a mean of 4.20 and a standard deviation of 0.57 (on a five-point scale) for customer orientation. Thus, even a standard deviation or two below the mean is still above the scale midpoint. It might be that employees who are recruited to work in a service context are likely to exhibit high levels of customer orientation, and that few of them will actually score as a low as a 1,2, or 3 on a five-point scale.

Sixth, we measured hospital-level service performance from two members of upper management at each hospital and not customer perceptions of service quality, loyalty, or satisfaction or more objective measures of performance. Future research should address this issue by obtaining direct information about customer satisfaction through the customers as well as more objective data regarding organizational performance.

A final limitation of this study is that we aggregated individual-level customer-focused voice data to create the hospital-level customer-focused voice measure. As Bliese (2000) suggests, this aggregation process leads to a more reliable measure of the construct of interest than using ratings from a single individual. However, this method may lead to a misalignment between the level of theory and the level of measurement. An alternative way to measure hospital-level customer-focused voice is to reword the items to refer to the hospital-level of analysis (e.g., Ehrhart, 2004; Podsakoff, Ahearne, \& MacKenzie, 1997). This method ensures that the 
level of theory and the level of measurement are consistent (Kozlowski \& Klein, 2000). We suggest that future work match the items to the appropriate level of analysis.

\section{Conclusions}

Our research seeks to theoretically and empirically advance the customer service and voice literatures. In making these contributions, this research has several strengths such as collecting data at three points in time from four different sets of organizational members (i.e., employees, managers, and CEOs/VPs of the hospitals) and testing the relationships using multilevel modeling at the appropriate level of analysis to take into account the nested nature of the data. These methodological strengths help to improve the validity of our study and the conclusions that we draw based on the results.

Given the turbulent and stumbling service-based global economy (particularly in the United States), it is critical for organizations to improve customer satisfaction. Our research suggests that it could be a strategic advantage for organizations to encourage their employees to speak up to management about issues that could help improve the customer experience. The findings contribute to our understanding of the conditions that encourage employees to engage in challenging forms of OCB, such as voice, and how such challenging behaviors can enhance levels of customer service quality.

\section{REFERENCES}

Aiken LS, West SG. (1991). Regression: Testing and interpreting interactions. Thousand Oaks, CA: Sage.

Ashford SJ, Barton MA. (2007). Identity-based issue selling. In Bartel CA, Blader S, Wrzesniewski A (Eds.), Identity and the modern organization (pp. 223-244). Mahwah, NJ: Erlbaum.

Ashford SJ, Rothbard NP, Piderit SK, Dutton JE. (1998). Out on a limb: The role of context and impression management in selling gender-equity issues. Administrative Science Quarterly, 43, 23-57.

Balliet D, Li NP, Joireman J. (2011). Relating trait self-control and forgiveness within prosocials and proselfs: Compensatory versus synergistic models. Journal of Personality and Social Psychology, 101, 1090-1105.

Bettencourt LA, Brown SW. (1997). Contact employees: Relationships among workplace fairness, job satisfaction, and prosocial service behaviors. Journal of Retailing, 73, $39-61$.

Bettencourt LA, Gwinner KP, Meuter ML. (2001). A comparison of attitude, personality, and knowledge predictors of service-oriented organizational citizenship behaviors. Journal of Applied Psychology, 86, 29-41.

Bliese PD. (1998). Group size, ICC values, and group-level correlations: A simulation. Organizational Research Methods, 1, 355-373. 
Bliese PD. (2000). Within-group agreement, non-independence, and reliability: Implications for data aggregation and analysis. In Klein KJ, Kozlowski SWJ (Eds.), Multilevel theory, research, and methods in organizations (pp. 349-381). San Francisco, CA: Jossey-Bass.

Bliese PD, Halverson RR, Schriesheim CA. (2002). Benchmarking multilevel methods: Comparing HLM, WABA, SEM, and RGR. Leadership Quarterly, 13, 3-14.

Bolino MC, Turnley WH. (2005). The personal costs of citizenship behavior: The relationship between individual initiative and role overload, job stress, and work-family conflict. Journal of Applied Psychology, 90, 740-748.

Brady MK, Cronin JJ. (2001). Customer orientation: Effects on customer service perceptions and outcome behaviors. Journal of Service Research, 3, 241-251.

Burris E. (2012). The risks and rewards of speaking up: Managerial responses to employee voice. Academy of Management Journal, 55, 851-875.

Campion MA, Medsker GJ, Higgs AC. (1993). Relations between work group characteristics and effectiveness: Implications for designing effective work groups. PERSONNEL PSYCHOLOGY, 46, 823-850.

de Jong A, de Ruyter K, Lemmink J. (2004). Antecedents and consequences of the service climate in boundary-spanning self-managing service teams. Journal of Marketing, $68,18-35$.

Detert JR, Burris ER. (2007). Leadership behavior and employee voice: Is the door really open? Academy of Management Journal, 50, 869-884.

Detert JR, Edmondson AC. (2011). Implicit voice theories: Taken-for-granted rules of self-censorship at work. Academy of Management Journal, 54, 461-488.

Dietz J, Pugh SD, Wiley JW. (2004). Service climate effects on customer attitudes: An examination of boundary conditions. Academy of Management Journal, 47, 8192.

Dimitriades ZS. (2007). The influence of service climate and job involvement on customeroriented organizational citizenship behavior in Greek service organizations: A survey. Employee Relations, 29, 469-491.

Donavan TD, Brown TJ, Mowen JC. (2004). Internal benefits of service-worker customer orientation: Job satisfaction, commitment, and organizational citizenship behaviors. Journal of Marketing, 68, 128-146.

Dutton JE, Ashford SJ. (1993). Selling issues to top management. Academy of Management Review, 18, 397-428.

Dutton JE, Duncan RB. (1987). The creation of momentum for change through the process of strategic issue diagnosis. Strategic Management Journal, 8, 279295.

Ehrhart MG. (2004). Leadership and procedural justice climate as antecedents of unit-level organizational citizenship behavior. PERSOnNel PsyChOLOGY, 57, 61-94.

Floyd SW, Wooldridge W. (1994). Dinosaurs or dynamos? Recognizing middle management's strategic role. Academy of Management Executive, 8, 47-57.

Frese M, Fay D. (2001). Personal initiative: An active performance concept for work in the 21 st century. In Staw BW, Sutton RL (Eds.), Research in organizational behavior (pp. 133-187). Stamford, CT: JAI Press.

Gelade GA, Ivery M. (2003). The impact of human resource management and work climate on organizational performance. PERSONNEL PSYCHOLOGY, 56, 383-404.

George JM, James LR. (1993). Personality, affect, and behavior in group revisited: Comment on aggregation, levels of analysis, and a recent application of within and between analysis. Journal of Applied Psychology, 78, 798-804.

Ginzel LE, Kramer RM, Sutton RI. (1993). Organizational impression management as a reciprocal influence process: The neglected role of the organizational audience. Research in Organizational Behavior, 15, 227-266. 
Grant AM, Mayer DM. (2009). Good soldiers and good actors: Prosocial and impression management motives as interactive predictors of affiliative citizenship behaviors. Journal of Applied Psychology, 94, 900-912.

Grant AM, Parker SK, Collins CG. (2009). Getting credit for proactive behavior: Supervisor reactions depend on what you value and how you feel. PERSONNEL PSYCHOLOGY, $62,31-55$.

Grizzle JW, Zablah AR, Brown TJ, Mowen JC, Lee JM. (2009). Employee customer orientation in context: How the environment moderates the influence of customer orientation on performance outcomes. Journal of Applied Psychology, 94, 12271242.

Groth M. (2005). Customers as good soldiers: Examining citizenship behaviors in internet service deliveries. Journal of Management, 31, 7-27.

Hackman JR, Oldham GR. (1976). Motivation through the design of work: Test of a theory. Organizational Behavior and Human Performance, 16, 250-279.

Hackman JR, Oldham GR. (1980). Work redesign. Reading, MA: Addison-Wesley.

Hirschman AO. (1970). Exit, voice, and loyalty: Responses to decline in firms, organizations, and states. Cambridge, MA: Harvard University Press.

Hong Y, Liao H, Hu J, Jiang K. (2013). Missing link in the service profit chain: A metaanalytic review of the antecedents, consequences and moderators of service climate. Journal of Applied Psychology, 98, 237-267.

Hui C, Lam SS, Schaubroeck J. (2001). Can good citizens lead the way in providing quality service? A field quasi experiment. Academy of Management Journal, 44, 988-995.

Hui CH, Chiu CKW, Yu LHP, Cheng K, Tse HHM. (2007). The effects of service climate and the effective leadership behavior of supervisors on frontline employee service quality: A multi-level analysis. Journal of Occupational and Organizational Psychology, 80, 151-172.

Ilies R, Nahrgang JD, Morgeson FP. (2007). Leader-member exchange and citizenship behaviors: A meta-analysis. Journal of Applied Psychology, 92, 269-277.

Johnson JW. (1996). Linking employee perceptions of service climate to customer satisfaction. Personnel PSYCHOLOGY, 49, 831-851.

Joireman J, Kamdar D, Daniels D, Duell B. (2006). Good citizens to the end? It depends: Empathy and concern with future consequences moderate the impact of a short-term time horizon on organizational citizenship behaviors. Journal of Applied Psychology, 91, 1307-1320.

Joshi A, Liao H, Jackson SE. (2006). Cross-level effects of workplace diversity on sales performance and pay. Academy of Management Journal, 49, 459-481.

Kelley SW. (1992). Developing customer orientation among service employees. Journal of Academy of Marketing Science, 20, 27-36.

Kozlowski SWJ, Klein KJ. (2000). A multilevel approach to theory and research in organizations: Contextual, temporal, and emergent processes. In Klein KJ, Kozlowski SWJ (Eds.), Multilevel theory, research, and methods in organizations: Foundations, extensions, and new directions (pp. 3-90). San Francisco, CA: Jossey-Bass.

Kreft I, De Leeuw J. (1998). Introducing multilevel modeling. London: Sage.

Lam CK, Huang X, Janssen O. (2010). Contextualizing emotional exhaustion and positive emotional display: The signaling effects of supervisors' emotional exhaustion and service climate. Journal of Applied Psychology, 95, 368-376.

LePine JA, Van Dyne L. (1998). Predicting voice behavior in work groups. Journal of Applied Psychology, 83, 853-868.

LePine JA, Van Dyne L. (2001). Voice and cooperative behavior as contrasting forms of contextual performance: Evidence of differential relationships with Big Five personality characteristics and cognitive ability. Journal of Applied Psychology, 86, 326-336. 
Liao H, Chuang A. (2004). A multilevel investigation of factors influencing employee service performance and customer outcomes. Academy of Management Journal, 47, $41-58$.

Liao H, Chuang A. (2007). Transforming service employees and climate: A multilevel, multisource examination of transformational leadership in building long-term service relationships. Journal of Applied Psychology, 92, 1006-1019.

Liao H, Subramony M. (2008). Employee customer orientation in manufacturing organizations: Joint influences of customer proximity and the senior leadership team. Journal of Applied Psychology, 2, 317-328.

Liden RC, Sparrowe RT, Wayne SJ. (1997). Leader-member exchange theory: The past and potential for the future. In Ferris GR (Ed.), Research in personnel and human resource management (Vol. 15, pp. 47-119). Greenwich, CT: JAI Press.

MacKenzie SB, Podsakoff PM, Podsakoff NP. (2011). Challenge-oriented organizational citizenship behaviors and organizational effectiveness: Do challenge-oriented behaviors really have an impact on the organization's bottom line? PERSONNEL PSYCHOLOGY, 64, 559-592.

Mayer DM, Ehrhart MG, Schneider B. (2009). Service attribute boundary conditions of the service climate-customer satisfaction link. Academy of Management Journal, 52, $1034-1050$.

McAllister DJ, Kamdar D, Morrison EW, Turban DB. (2007). Disentangling role perceptions: How perceived role breadth, discretion, instrumentality, and efficacy relate to helping and taking charge. Journal of Applied Psychology, 92, 1200-1211.

McKay PF, Avery DR, Liao H, Morris MA. (2011). Does diversity climate lead to customer satisfaction? It depends on the service climate and business unit demography. Organization Science, 22, 788-803.

Meglino BM, Kosgaard A. (2004). Considering rational self-interest as a disposition: Organizational implications of other orientation. Journal of Applied Psychology, 89, 946-959.

Milliken FJ, Morrison EW, Hewlin PF. (2003). An exploratory study of employee silence: Issues that employees don't communicate and why. Journal of Management Studies, 40, 1453-1476.

Moon H, Kamdar D, Mayer DM, Takeuchi R. (2008). Me or we? The role of personality and justice as other-focused antecedents to innovative citizenship behaviors within organizations. Journal of Applied Psychology, 93, 84-94.

Morrison EW. (2011). Employee voice behavior: Integration and directions for future research. Academy of Management Annals, 5, 373-412.

Morrison EW, Milliken FJ. (2000). Organizational silence: A barrier to change and development in a pluralistic world. Academy of Management Review, 25, 706-725.

Morrison EW, Phelps CC. (1999). Taking charge at work: Extrarole efforts to initiate workplace change. Academy of Management Journal, 42, 403-419.

Olson-Buchanan JB, Boswell WR. (2002). The role of employee loyalty and formality in voicing discontent. Journal of Applied Psychology, 87, 1167-1174.

Payne SC, Webber SS. (2006). Effects of service provider attitudes and employment status on citizenship behaviors and customers' attitudes and loyalty behavior. Journal of Applied Psychology, 91, 365-378.

Perlow L, Williams S. (2003). Is silence killing your company? Harvard Business Review, $81,52-58$.

Podsakoff NP, Ahearne M, MacKenzie SB. (1997). Organizational citizenship behavior and the quantity and quality of work group performance. Journal of Applied Psychology, $82,262-270$. 
Podsakoff NP, Whiting SW, Podsakoff PM, Blume BD. (2009). Individual- and organizational-level consequences of organizational citizenship behaviors: A metaanalysis. Journal of Applied Psychology, 94, 122-141.

Podsakoff PM, MacKenzie SB, Paine JB, Bachrach DG. (2000). Organizational citizenship behaviors: A critical review of the theoretical and empirical literature and suggestions for future research. Journal of Management, 26, 513-563.

Rafaeli A, Ziklik L, Doucet L. (2008). The impact of call center employees' customer orientation behavior on service quality. Journal of Service Research, 10, 239-255.

Raub S, Liao H. (2012). Doing the right thing without being told: Joint effects of initiative climate and general self-efficacy on employee proactive customer service performance. Journal of Applied Psychology, 97, 651-667.

Raudenbush SW, Bryk AS, Cheong YF, Congdon RT. (2001). HLM5: Hierarchical linear and nonlinear modeling. Lincolnwood, IL: Scientific Software International.

Rodriguez NG, Perez MJS, Gutierrez JAT. (2008). Can a good organizational climate compensate for a lack of top management commitment to new product development? Journal of Business Research, 61, 118-131.

Saavedra RP, Earley C, Van Dyne L, Lee C. (1993). Complex interdependence in taskperforming groups. Journal of Applied Psychology, 71, 61-72.

Salancik GR, Pfeffer J. (1978). A social information processing approach to job attitudes and task design. Administrative Science Quarterly, 23, 224-253.

Salanova M, Agut S, Peiro JM. (2005). Linking organizational resources and work engagement to employee performance and customer loyalty: The mediation of service climate. Journal of Applied Psychology, 90, 1217-1227.

Saxe R, Weitz BA. (1982). The SOCO scale: A measure of the customer orientation of sales people. Journal of Marketing Research, 19, 343-351.

Schneider B. (1975). Organizational climates: An essay. Personnel Psychology, 28, 447-479.

Schneider B, Ehrhart MG, Mayer DM, Saltz JL, Niles-Jolly K. (2005). Understanding organization-customer links in service settings. Academy of Management Journal, 48, 1017-1032.

Schneider B, White SS, Paul MC. (1998). Linking service climate and customer perceptions of service quality: Test of a causal model. Journal of Applied Psychology, 83, 150163.

Seibert SE, Kraimer ML, Crant JM. (2001). What do proactive people do? A longitudinal model linking proactive personality and career success. PERSONNEL PSYCHOLOGY, 54, 845-874.

Spreitzer GM. (1995). Psychological empowerment in the workplace: Dimensions, measurement, and validation. Academy of Management Journal, 38, 1442-1465.

Susskind AM, Kacmar KM, Borchgrevink CP. (2003). Customer service providers' attitudes relating to customer service and customer satisfaction in the customer-server exchange. Journal of Applied Psychology, 88, 179-187.

Tangirala S, Ramanujam R. (2008). Exploring nonlinearity in employee voice: The effects of personal control and organizational identification. Academy of Management Journal, $51,1189-1203$.

Van Dyne L, Ang S, Botero IC. (2003). Conceptualizing employee silence and voice as multidimensional constructs. Journal of Management Studies, 40, 1359-1392.

Van Dyne L, Cummings LL, Parks JM. (1995). Extra-role behaviors: In pursuit of construct and definitional clarity (a bridge over muddied waters). In Cummings LL, Staw BM (Eds.), Research in organizational behavior (Vol. 17, pp. 215-285). Greenwich, CT: JAI Press. 
Van Dyne L, LePine JA. (1998). Helping and voice extra-role behaviors: Evidence of construct and predictive validity. Academy of Management Journal, 41, 108119.

Venkataramani V, Tangirala S. (2010). When and why do central employees speak up? An examination of mediating and moderating variables. Journal of Applied Psychology, 95, 582-591.

Walz SM, Niehoff BP. (2000). Organizational citizenship behaviors: Their relationship to organizational effectiveness. Journal of Hospitality and Tourism, 24, 108-126.

Whiting SW, Maynes TD, Podsakoff NP, Podsakoff PM. (2012). Effects of message, source, and context on evaluations of employee voice behavior. Journal of Applied Psychology, 97, 159-182.

Withey MJ, Cooper WH. (1989). Predicting exit, voice, loyalty, and neglect. Administrative Science Quarterly, 34, 521-539.

Wrzesniewski A, Dutton J. (2001). Crafting a job: Employees as active crafters of their work. Academy of Management Review, 26, 179-201.

Yen HR, Niehoff BP. (2004). Organizational citizenship behaviors and organizational effectiveness: Examining relationships in Taiwanese banks. Journal of Applied Social Psychology, 34, 1617-1637. 